\title{
Evaluating the effectiveness of employment assistance measures: case of Russian state employment centers
}

\author{
Tatiana Stuken \\ Dostoevsky Omsk State University, Omsk, Russia \\ Olga Korzhova \\ Dostoevsky Omsk State University, Omsk, Russia
}

\begin{abstract}
Russia is currently implementing the national project "Labor productivity and employment support", which is a set of measures aimed at developing employment infrastructure and introducing organizational and technological innovations to support employment, including standard solutions aimed at improving the efficiency of state employment centers. This project defines the strategic directions of state regulation of the Russian labor market.

This article deals with the issues of the population's demand for the services of employment centers, including not only registering as unemployed but also receiving public services to assist in finding a suitable job, vocational training, psychological support, etc. The study is based on the Russian labor force survey and microdata of employment centers for 2019 (more than 24,000 observations). Based on the data from the labor force survey, conclusions are drawn about the demand for the state employment centers' services among various groups of the population and about typical combinations of applying to the employment service with other job search channels. The analysis of regional microdata made it possible to evaluate the performance of employment centers based on information about the socio-demographic characteristics of the unemployed, the duration of the unemployment status, the fact of receiving benefits, the services received and the reasons for de-registration. Based on the results of the analysis, conclusions are made about the ways to improve the work of the state employment centers.
\end{abstract}

\section{Keywords}

active labor market policies, state employment centers

\section{Introduction}

Development priorities of the Russian Federation until 2024 are defined by a series of national projects, one of which is the national project "Labor productivity and employment support". An integral part of this project is the modernization of employment centers, improving the efficiency of their work and the quality of services they provide to the population.

By the legislation of the Russian Federation, employment centers are assigned the following main functions:
- informing citizens about the situation on the labor market, rights and guarantees in the field of employment, and protection from unemployment;

- development and implementation of programs that provide for measures to promote employment;

- assistance to citizens in finding a suitable job, and to employers in selecting the necessary employees;

- organization of measures of active employment policy of the population;

- implementation of social allowances to 
citizens recognized as unemployed following the established procedure (Employment of the population in the Russian Federation, 1991).

Employment centers pay special attention to the implementation of active labor market policy (ALMP). These measures usually include training for the unemployed, subsidized employment, assistance in finding work, including referrals to employers, and free access to the job database (Martin, 2015; Mušikić, Marčetić, Đurović, 2017). Training of the unemployed is becoming important in the context of the knowledge economy and has a major impact on the labor market and the economy in general (Hadad, 2018).

In accordance with Russian legislation, within the framework of ALMP, employment centers provide a wide range of services: informing about the situation on the labor market, assistance in finding a job, temporary employment, organization of public works, professional guidance, vocational training and additional professional education, psychological support and social adaptation services for the unemployed, conducting job fairs, assistance in selfemployment, assistance in moving to another area, support for the employment of disabled people.

Considering the role of employment centers in the Russian labor market, it is important to note several features.

1. There is a large gap between the overall unemployment rate, which is recorded by statistical agencies in accordance with international standards, and the unemployment rate recorded by employment centers. So, at the end of 2019 on average, total unemployment in Russia exceeded the registered unemployment rate by more than 4 times.

2. The low rate of replacement of wages with unemployment benefits reduces the demand for employment centers' services. Until 2020 the amount of unemployment benefits varied in the range of 15.1-87.1\$ with an average salary of $544.8 \$$ in terms of the official exchange rate of the Central Bank of Russia (the authors' calculations). In particular, the minimum benefit is available to unemployed people who have no work experience, have been dismissed for culpable actions, are long-term unemployed, have been informally employed by a previous employer and, for this reason, are not able to submit a certificate of average salary.
3. Perception of employment centers by labor market agents as generally ineffective bureaucratic structures. Applying to an employment center is not the most popular way to find a job (Gruznykh, 2015).

4. There is no real alternative to applying to employment centers in case of a difficult life situation and economic crisis. Only citizens who have applied to employment centers can claim unemployment benefits, free vocational training and assistance in organizing their own business. In addition, an early retirement pension may be issued for persons of pre-retirement age who cannot find a job.

Priorities of state policy, combined with significant financial resources, actualize the need to assess the effectiveness of employment centers. In Russia there is a task to develop employment infrastructure and introduce organizational and technological innovations using digital and platform solutions to support the employment level of population. In particular, it means the development of common requirements for the activities of employment centers, including standard solutions and recommendations for improving the efficiency of employment centers, the standard of the model employment center, regulations for the work of employment centers, the implementation and organizational and methodological support of information systems. As part of the implementation of national projects and tasks aimed at supporting employment, the Russian government plans to allocate 12.7 billion rubles (Passport of the national project (program) "Productivity and employment support", 2018).

\section{Literature review}

Assessment of the effectiveness of employment centers can be carried out at the macro and micro levels.

In the first case, the effect of individuals' participation in employment center programs is estimated, which can be expressed, for example, in changes in the probability of getting a job, the onset of a repeated period of unemployment, its duration of unemployment, etc. (Vooren et al., 2019). Many researchers have recorded a small positive effect from the implementation of active employment policy measures (Crépon, van den Berg, 2016; Card et al., 2018). At the same time, it is noted that different programs of employment centers have different microeconomic efficiency. For example, it is shown that assistance in finding a job has the greatest impact on improving the 
position of labor market participants (Kluve, 2010; Vooren et al., 2019).

The macroeconomic effects of employment center programs are analyzed in the context of the unemployment rate and are usually based on cross-country (inter-regional) comparisons. Thus, based on an analysis of data from $21 \mathrm{EU}$ countries, A. Bánociová et al. (2017) found that increases in spending on active employment policy programs were not significantly reflected in changes in the unemployment rate. In the work of L. Benda et al. (2019) it was revealed that the effectiveness of an active employment policy depends on institutional factors, namely, the strictness of employment protection legislation and the "generosity" of unemployment benefits. Programs aimed at helping people start their own businesses are highly dependent on providing high-quality social infrastructure, which has a positive impact on both employment and local entrepreneurship (Chivu, 2019). Active employment programs have different effects on long-term unemployment, depending on the institutional configuration of the labor market. Government employment and training programs help reduce long-term unemployment with stricter employment protection laws. Employment programs become more effective when the "generosity" of unemployment benefits decreases.

\section{Research methods}

Currently, Russian regions are evaluating the activities of employment centers. However, the analysis of used indicators and criteria shows that often, the focus in the evaluation is more on internal processes than on the effects for beneficiaries and the labor market in general. Here are some indicators for evaluating the performance of Russian employment centers:

- indicators for core business: performance of the state task on the provision of public services, the achievement of established performance indicator

- indicators of financial and economic activity: the volume of changes in the budget estimates, the share of unfulfilled budget funds;

- indicators of personnel performance: staffing; turnover rate of the staff of the employment centers.

This list shows that the evaluation of employment centers is largely aimed at solving internal problems and performing discipline. The assessment of the main activity of employment centers is also formalized, taking into account the number of completed works, but not their results. This assessment does not make it possible to understand which measures and for which groups of the unemployed are most effective, and how, with data on the use of measures in previous periods, to build measures to promote employment in relation to new unemployed.

It is obvious that to answer these questions, it is necessary to assess the effectiveness of ALMP measures in relation to various socio-demographic groups of the unemployed.

In this paper, an attempt is made to evaluate the activity of the employment service from the perspective of service recipients on the example of one of the 85 Russian regions based on data available in employment centers and state statistics bodies. This region can be called a typical region of the country based on its total population, share of urban population, education level, employment structure, and unemployment rate. Its indicators approximately correspond to the national average, or deviate from the national average within one standard deviation. The characteristics of employment centers may reflect the situation in other Russian regions, both because of the typical nature of this region, and because of the existence of national formal rules governing their work.

The purpose of this study is to evaluate the effectiveness of employment centers at the micro level using statistical data, as well as to determine on this basis the directions for improving the activities of employment centers.

It is important to note that such an assessment objectively faces several difficulties.

In the microeconomic assessment of the effectiveness of employment centers, it is important to have an information base with the characteristics of individuals who have applied to employment centers, containing information about the services they receive and the reasons for deregistration. The quality of the assessment is largely determined by the quality of the information base.

Qualitative analysis involves not only an assessment of what services the employment centers provided to the individual and for what reasons he was removed from the register in the employment center, but also how his position in the labor market changed after a certain period. For example, the effectiveness of the employment center, all other things being equal, will be evidenced by the presence of stable paid 
employment, while job loss and long-term repeated unemployment, on the contrary, will reduce the effectiveness estimates. However, the analysis of an individual's position in the labor market after being deregistered in an employment center is difficult both because of the legislation on personal data protection, which requires the individual's prior consent to collect information, and because the individual may refuse to answer questions or change their contact information, etc.

This is why in this study, the tasks of evaluating the effectiveness of employment centers are adjusted to take into account the available information. We have two microdata databases at our disposal that are used to build estimates.

1. Database of the 2017-2018 monthly sample survey of the labor force, representative for each of the Russian regions. It contains information about the socio-demographic characteristics of the population (gender, age, education, place of residence, classification as unemployed), methods of job search. This research is carried out by state statistics bodies. A sub-sample of people living in the region and classified as unemployed by international standards amounted to 129.4 thousand observations.

2. Microdata of regional employment centers containing information about the sociodemographic characteristics of individuals registered as unemployed (gender, age, education, place of residence), the date of registration and deregistration (if available), the list of services used by the unemployed, the reasons for deregistration. This database includes individuals who applied to employment centers in the region in 2019 (this is the general population, more than 24.0 thousand observations).

The available data allow us to evaluate the effectiveness of employment centers for individuals in the following areas:

1. Availability of employment centers services for the population. The location of employment centers and the list of documents required to register an individual as unemployed and to assign benefits may create certain barriers, especially for people with low education levels and living in rural areas with low population density. In the latter case, the unemployed are forced to bear additional time and money costs associated with trips to the employment center located in another locality.

2. Reasons for deregistration of the unemployed, which may characterize the usefulness of the services received for individuals. For example, the reasons that can characterize a positive impact on the position of an individual in the labor market include various employment options, vocational training (following Russian legislation, vocational training is the basis for deregistration of an unemployed person), as well as the organization of their own business (business activity). Negative assessments of the employment service's performance may be related to such reasons for deregistration as refusal of employment center services, or long-term absence from the employment center without a valid reason. The difference between these reasons is that in the first case, the person receives unemployment benefits, and in the second case does not.

3. The list and number of activities carried out by employment centers concerning the unemployed and their impact on the reasons for deregistration. It is especially important in this context to understand which of the measures have a positive impact on the fact of employment of an unemployed person.

The following analysis methods are used: descriptive statistics, as well as regression analysis (logistic regression).

\section{Research results}

Left without a job, individuals usually try to use several channels of job search (searching for vacancies via the Internet, contacting friends, relatives and acquaintances, directly contacting the employer, contacting the state employment center, or a commercial company that provides employment assistance services). The average unemployed person uses 2.45 job search channels. Just under a third of the unemployed - $32.4 \%$ apply to state employment centers. However, there are certain correlations of the selected job search channels. Factor analysis (extraction method: principal component analysis, rotation method: varimax with Kaiser normalization) identifies two components, the first of which is correlated with access to friends, relatives and acquaintances, access to the media, the Internet $(0.804$ and 0.746 , respectively, $32.8 \%$ of variation). The second component is correlated with applying to the state employment center $(0.798,22.4 \%$ of variation $)$.

For analysis of accessibility of services of employment centers, we used data from the labor force survey. The frequency of calls to 
employment centers by socio-demographic characteristics is shown in table 1 .

Table 1 Using the services of employment centers when searching for a job (\% of the number of unemployed in the corresponding group)

\begin{tabular}{|c|c|c|}
\hline Factor & $\begin{array}{l}\text { Searching } \\
\text { for a job with } \\
\text { the help of } \\
\text { an } \\
\text { employment } \\
\text { center }\end{array}$ & $\begin{array}{l}\text { Searching } \\
\text { for a job } \\
\text { without the } \\
\text { help of an } \\
\text { employment } \\
\text { center }\end{array}$ \\
\hline \multicolumn{3}{|l|}{ Residence } \\
\hline city & 25,8 & 74,2 \\
\hline rural area & 46,5 & 53,5 \\
\hline \multicolumn{3}{|l|}{ Gender } \\
\hline male & 32,7 & 67,3 \\
\hline female & 32,1 & 67,9 \\
\hline \multicolumn{3}{|l|}{ Age } \\
\hline under 30 years old & 25,8 & 74,2 \\
\hline from 30 to 50 years old & 39,9 & 60,2 \\
\hline From 50 to 60 years old & 37,0 & 63,0 \\
\hline \multicolumn{3}{|l|}{ Level of education } \\
\hline no professional education & 29,4 & 70,6 \\
\hline $\begin{array}{l}\text { secondary professional } \\
\text { education }\end{array}$ & 35,5 & 64,5 \\
\hline higher education & 32,1 & 67,9 \\
\hline Total & 32,4 & 67,6 \\
\hline
\end{tabular}

According to the table, it can be concluded that rural residents use the services of employment centers more often than urban residents. This may be due to limited opportunities to find work in rural areas and lower-income levels of rural residents, which makes the services of employment centers more attractive. We also note that the services of employment centers are much less attractive to young people. With no work experience, young people can often only rely on the minimum amount of unemployment benefits. At the same time, the table does not confirm the widespread opinion that employment centers are mainly used by low-skilled workers. It is employees without professional education who are less likely to become clients of employment centers. This fact requires further study. The reasons for this situation may be, for example, lower awareness of this group of unemployed, a high prevalence of informal employment, the complexity of bureaucratic procedures, etc.

A more accurate assessment of the availability of employment centers services for unemployed individuals was performed using a binary logistic regression, which also included variables that characterize the individual's marital status, the reasons for the loss of previous work and the group of occupations at the last job, and the duration of unemployment. The results of the research generally confirmed the data of descriptive statistics. All other things being equal, urban residents are less likely to apply to employment centers, and those who are married, have children, those who are over 30 years old, and those who have lost their jobs due to staff cuts and the end of the contract are more likely to apply to employment centers (in all cases $\mathrm{p}<0.01$ ).

Employment centers have the most complete statistics for the unemployed, which allows us to analyze the reasons for their deregistration (table 2).professional education are more likely to apply to employment centers than those without professional education $(\mathrm{p}<0.01)$. Individuals who have held positions of managers and mid-level specialists apply to employment centers less often than people who previously worked in the jobs of skilled and unskilled workers $(\mathrm{p}<0.01)$. However, all other things being equal, highly qualified specialists apply to employment centers more often than skilled and unskilled workers $(\mathrm{p}<0.01)$. This may probably be due to the specifics of the labor market and the oversupply of highly qualified specialists.

Unexpected results were obtained when analyzing the impact of applying to the employment service and the duration of unemployment. It is logical to assume that the need for employment center services should increase as the duration of unemployment increases. However, no such link was found. On the contrary, the need for employment center services decreases with increasing duration of unemployment $(\mathrm{p}<0.01)$. One of the reasons for this may be the declining size of the already low unemployment benefit, up to its complete cancellation.

The socio-demographic structure of the unemployed registered in employment centers is shifted towards a larger proportion of people who are particularly in need of social protection. For example, among the registered unemployed, 5.5\% have a disability, and $15.9 \%$ are of pre-retirement age (less than five years before the pension is granted). Of course, this feature has a significant impact on the work with clients of employment centers and on its effectiveness.

Let us look at the reasons for deregistration of the unemployed. 


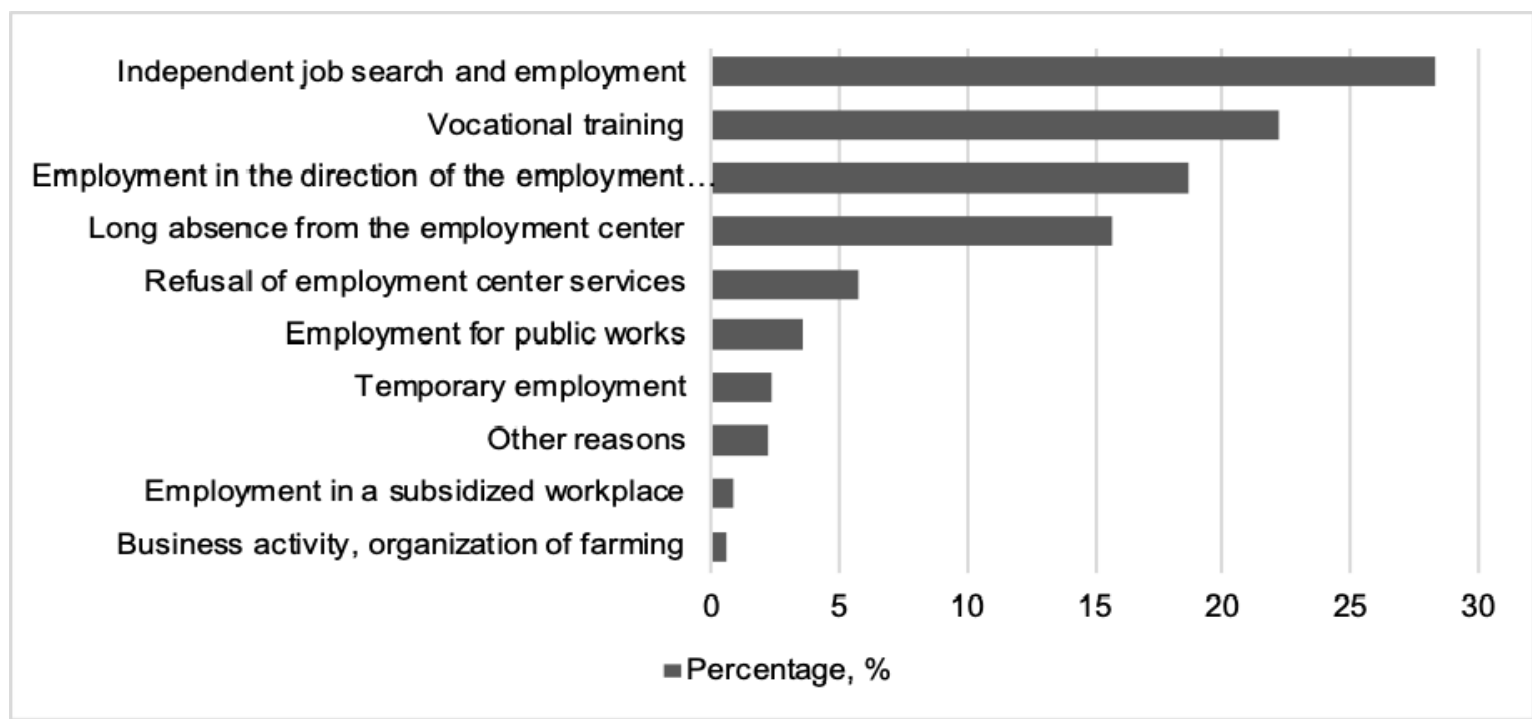

Figure 1 Distribution of reasons for deregistration of the unemployed in employment centers (\% of the number of cases) Source: The authors

More than half of the unemployed (53.53\%) are deregistered for employment reasons. However, a significant part of employment is not directly related to employment centers' activities. Independent job search and employment accounts for more than half of all employment $(52.8 \%)$. However, this does not indicate the inefficient work of employment centers, since a number of provided services are aimed at improving the competitiveness of the unemployed. Unemployed people are taught to make a resume and given recommendations for interviewing and selfpresentation.

Obtaining a professional education in accordance with Russian law, although it is the basis for the deregistration of an unemployed person, does not indicate that the unemployed person will find a job in a new profession or any other job. According to our data, a significant part of the unemployed who were deregistered after completing vocational training are re-registered in the employment centers, but the subsequent registration does not always record the cases of previous appeals, but only in relation to certain categories of citizens who are particularly in need of social protection (for example, the disabled, persons of pre-retirement age, released workers, and some other groups).

According to the data, every fifth unemployed person is deregistered either by writing an application to refuse the services of the employment center or because of a long absence from the employment center for no valid reason.
Despite the negative nature of such reasons for de-registration, the actual situation may be somewhat more complicated. For example, a long absence may be related to the fact that an unemployed person who does not receive benefits is employed. In this situation, the unemployed person is not obliged to inform the employment center about their employment.

Unfortunately, employment centers do not have the necessary resources to track the further trajectories of the unemployed in the labor market, which would allow us to more accurately determine the effect of provided services after a certain period, for example, a year.

It should be noted that other reasons for deregistration include such as conscription into the armed forces, the appointment of a pension, moving to another area, detection of attempts to obtain fraudulently, death, etc.

To assess the effectiveness of employment centers, it is important to analyze the services provided to clients by employment centers and identify their relationship to the reasons for deregistration. Available information shows that the frequency of service provision is uneven. For example, almost all unemployed people receive services related to informing about the situation on the labor market and assistance in finding a suitable job (more than 95\%), professional guidance (more than $80 \%$ ). At the same time, other services are provided much less frequently (figure 2). The average number of services received by one unemployed person is 4.2 . 


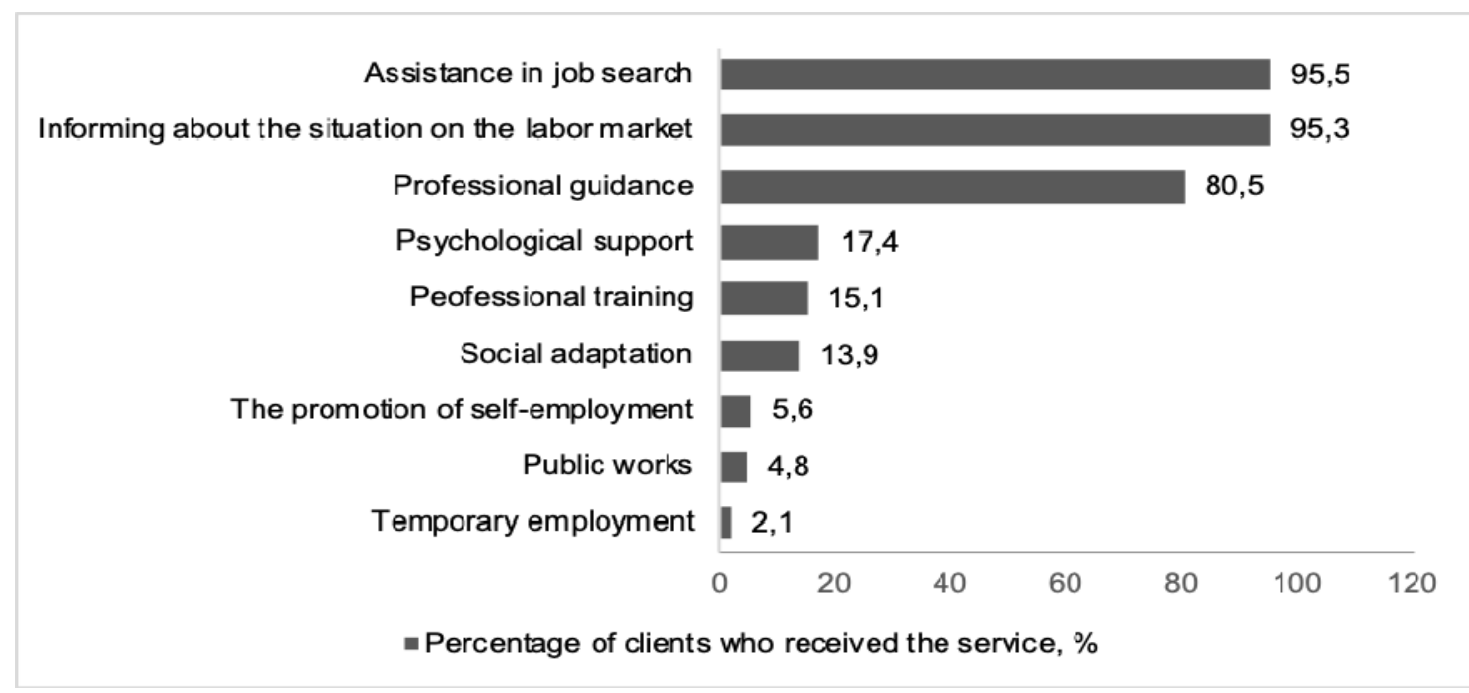

Figure 2 Distribution of employment centers' services by frequency of their provision (\% of clients who received the corresponding service) Source: The authors

The frequency of reasons for deregistration of citizens in need of special social protection differs significantly from the average. Thus, 9.8 times more often than other categories of the unemployed, they are employed in subsidized jobs, 3.4 times more often receive temporary employment. They find a permanent job almost 4 times less often and 3 times less often undergo vocational training. People of pre-retirement age are almost 10 times more likely than others to get temporary work. At the same time, they are 1.3 times more likely to find a job in the direction of the employment service compared to the average indicators, slightly higher than the average to complete vocational training (1.1 times). At the same time, it should be noted that for both groups of the population, the services of employment centers are less attractive compared to the average indicators, since the refusal of employment centers is 1.3 times more common for disabled people and 4.1 times more common for people of pre-retirement age.

To analyze the impact of services received on the reasons for deregistration, we used logistic regression models. The main reasons for deregistration were consistently used as dependent variables:

1. Independent job search or employment in the direction of the employment service. Both options can characterize the clients of the employment center as having sufficient competitiveness in the labor market (model 1).
2. Employment in subsidized jobs, public works (for some groups of the unemployed, such work is appropriate under Russian law), temporary employment of people who are experiencing difficulties in finding a job. Such employment is less stable and less preferable for the individual (model 2).

3. Professional training. Following Russian legislation, employment centers send to professional training those citizens who do not have a profession, cannot find a job in their existing profession or qualification or have lost the ability to perform work in their existing profession, qualification (model 3).

We have divided the factors that influence the reasons for deregistration into two groups. The first category includes characteristics of individuals. They include place of residence (a large city that is the administrative center of the region, or other localities), gender of the respondent (male, female), age (under 25 years, 25-40 years, from 40 years to pre-retirement age; pre-retirement age (according to Russian legislation, it includes the age corresponding to five or fewer years before the age of retirement); level of education (higher, secondary professional, no professional education); duration of the unemployment period (up to 1 month, 1-3 months, 3-6 months, more than 6 months), experience in the labor market (up to 1 year or more), health status (presence or absence of disability), repeated application to the employment center. The second group includes 
the services of employment centers provided to the unemployed, with the exception of those that, for certain reasons, are either mandatory or cannot be provided. These services include selfemployment promotion (for all models), referral to vocational training (for all models), temporary employment (for all models), and participation in public works for model 2.

Table 2 Influence of various factors on the probability of deregistration of the unemployed by reason

\begin{tabular}{|c|c|c|c|}
\hline ndependent variables (factors) & Model 1 & Model 2 & Model 3 \\
\hline \multicolumn{4}{|l|}{ Services of employment centers: } \\
\hline Social adaptation & $0.14^{* * *}$ & $0.34^{\star \star \star}$ & $0.59^{* * *}$ \\
\hline blic works & $-1.04^{\star \star \star}$ & & $-1.09^{\star \star \nu}$ \\
\hline Assistance in job search & $0.26^{\star \star \star}$ & -0.31 *** & \\
\hline ychological support & -0.05 & -0.06 & $0.81^{* * *}$ \\
\hline Professional guidance & $-0.49^{* \star *}$ & $-0.48^{* * *}$ & $1.34^{\star \star \star}$ \\
\hline \multicolumn{4}{|l|}{ Characteristics of respondents: } \\
\hline $\begin{array}{l}\text { Place of residence (regional center - } \\
\text { ef.) }\end{array}$ & $-0.59^{\star * *}$ & $-1.16^{* *}$ & -0.29 \\
\hline Gender (female - ref.) & $-0.06^{*}$ & $-0.17^{\star * *}$ & $0.33^{\star \star \star}$ \\
\hline \multicolumn{4}{|l|}{$\begin{array}{l}\text { Education (no professional } \\
\text { education - ref.): }\end{array}$} \\
\hline Higher & $0.62^{\star \star \star}$ & $-1.02^{* * *}$ & $-0.61^{\text {**1}}$ \\
\hline Secondary professional education & $0.17^{* * *}$ & $-0.27^{* * *}$ & $-0.28^{\star \star \prime}$ \\
\hline \multicolumn{4}{|l|}{$\begin{array}{l}\text { Age ( } 40-50 \text { for women, } 40-55 \text { for } \\
\text { men - ref.): }\end{array}$} \\
\hline Age up to 25 years & -0.10 & $-0.90^{* * *}$ & $0.39^{\star \star \star}$ \\
\hline Age from 25 to 40 years & -0.03 & -0.18 & 0.08 \\
\hline $\begin{array}{l}\text { Dre-retirement age (51-55 for } \\
\text { Nomen, } 56-60 \text { for men) }\end{array}$ & $-0.77^{* * *}$ & $1.12^{\star \star \star}$ & $-0.56^{* * \prime}$ \\
\hline Disability (absence - ref.) & $-0.85^{\star \star}$ & $1.28^{\star \star \star}$ & $-0.83^{\star * *}$ \\
\hline $\begin{array}{l}\text { Work experience in the labor market } \\
\text { or a year or less (more than } 1 \text { year } \\
\text { ref.) }\end{array}$ & $-0.60^{* * \prime}$ & $0.37^{* * *}$ & $0.26^{* * *}$ \\
\hline $\begin{array}{l}\text { Repeated application to the } \\
\text { employment center (primary - ref.) }\end{array}$ & 0.08 & 0.17 & $0.28^{* * *}$ \\
\hline \multicolumn{4}{|l|}{$\begin{array}{l}\text { Duration of the unemployment } \\
\text { period (more than } 6 \text { months - ref.): }\end{array}$} \\
\hline up to 1 month & $1.67^{\star \star *}$ & $1.83^{* * *}$ & $1.93^{* \star \star}$ \\
\hline rom 1 to 3 months & $1.36^{* \star \star}$ & $1.66^{* * *}$ & $1.53^{* \star \star}$ \\
\hline rom 3 to 6 months & $1.70^{* * *}$ & $1.79^{* * *}$ & $1.18^{* * *}$ \\
\hline Vagelkerke R-square & 0.35 & 0.20 & 0,49 \\
\hline
\end{tabular}

Source: The authors

Let us look at the main results. For convenience, table 2 shows only statistically significant estimates of regression parameters and the direction of the variable's influence on the result. According to the data, in all the models considered, the provision of social adaptation services in the labor market, which allows the unemployed to learn how to make a resume, search for a job independently, prepare for an interview, etc., has a positive effect on the deregistration of the unemployed. The other services considered also have a certain effect, but not in all cases. For example, providing professional guidance is effective only if the unemployed person then agrees to take the professional training. Probably, the individual's awareness of the need to change the type of activity leads to the fact that the psychological support service, in this case, has a statistically significant positive impact. Assistance in searching for a job has an effect if the unemployed person has sufficient competitiveness to allow him to apply for a job on an equal basis with other individuals.

Let us also draw attention to the results obtained with regard to the participation of the unemployed in public works. The negative impact on deregistration in the first and third models may be due to the fact that participation in public works distracts the unemployed from participating in other programs.

As for the socio-demographic characteristics of the respondents, their estimates were generally expected. Lower employment rates in the regional center indicate that in a large city that has more opportunities in the labor market; individuals have more opportunities to find work without applying to employment centers. In other words, in the regional center, when applying to the employment center, there is a self-selection effect, while in small localities it is much weaker. The effect of self-selection, in our opinion, can be explained by the higher rates of employment in the regional center of women compared to men.

Despite a number of measures taken by the state, disabled people and people of pre-retirement age remain the problem group, who have less chance of employment and training. Their more active employment in temporary jobs and participation in public works partially compensates for the objectively lower competitiveness of this group of unemployed, as well as discrimination in the Russian labor market, including age discrimination.

\section{Conclusion}

The analysis makes it possible to conclude that the services of employment centers are available to the population, regardless of the place of residence. At the same time, it is important to pay attention to the availability and attractiveness of services for young people and people with low levels of education - groups that traditionally have higher than average unemployment rates.

The majority of the unemployed are deregistered in employment centers in connection with employment. However, the quality of employment varies significantly. Almost $47 \%$ of the unemployed find work either on their own or 
in the direction of employment centers. The remaining part of the employed $(6.6 \%)$ is employed in less stable jobs - temporary work, subsidized jobs, and public works. More often than other groups of unemployed, this reason is typical for people of pre-retirement age who do not have work experience, and disabled people groups that are particularly in need of assistance from the state.

A positive characteristic of the activity of the employment service can also serve as professional training for $15 \%$ of unemployed citizens. Most often, this service is used by young people and people who have repeatedly applied to the employment center. The data also shows that the indicators of employment and professional training are statistically significantly lower for the unemployed, whose duration of job search exceeds six months. A more in-depth analysis of this group is required, including their motivation to find work and the specifics of local labor markets.

We should also note the problems associated with the fact that the activity of employment centers does not fully meet the expectations of citizens. Among the indicators of these problems, it can be noted that every fifth unemployed person stops using the services of the employment center before reaching the goal of applying. Thus, improving the efficiency of employment centers can be associated with the following actions.

First, it is necessary to improve the quality of information support for the activities of employment centers in terms of recording information about persons registered as unemployed. It is important to record not only current requests, but also establish links with records of requests from earlier periods.

Second, some of the information related to job search and participation in activities conducted by employment centers remains unformalized, and, as a result, is lost in the analysis. Perhaps it is necessary to briefly record the results of participation in events, or the reasons for refusing to participate in them.

Third, it is important to set up feedback channels with the unemployed, since the high percentage of refusals from employment centers' services and long absences of the unemployed to employment centers require study. Their analysis can provide important information for improving the performance of the employment centers.

Fourth, it is important to regularly conduct research on the situation in the labor market of persons who have been deregistered from the employment center. This is how you can evaluate the subsequent trajectories of individuals related to job search, employment, job changes, salary levels, job satisfaction, etc. By recording these data and correlating it with active employment policy measures, it is possible to understand which of the measures ultimately contributed to the construction of more or less successful trajectories in the labor market.

Fifth, having these data, it is possible to predict the effectiveness of certain measures for the success of employment of persons belonging to specific socio-demographic groups. The availability of such information can significantly reduce the resources associated with the construction of a job search plan, increase the effectiveness of employment centers and use modern methods of data analysis.

Sixth, changes in technologies for working with the unemployed, in particular through the use of online technologies that reduce the time and financial costs of rural residents and thus increase the availability of services, would help to improve the performance of employment centers.

The implementation of the proposed measures will make it possible to contribute to the solution of the strategic task of creating highly effective employment centers.sm

\section{Acknowledgements}

The reported study was funded by RFBR, project number 20-010-00489.

\section{References}

Banociova, A. \& Ťahlová, S. (2017). Active Labour Market Policies of Selected European Countries and Their Competitiveness. Journal of Competitiveness, 9, 5-21. https://doi.org/10.7441/joc.2017.03.01

Benda L., Koster F.\& van der Veen R. (2019). Activation is not a panacea: active labour market policy, long-term unemployment and institutional complementarity. Journal of Social Policy, 1-24. https://doi.org/10.1017/S0047279419000515

Card, D. E., Kluve, J. \& Weber, A.M. (2018) What Works? A Meta Analysis of Recent Active Labor Market Program Evaluations. Journal of the European Economic Association, 16 (3), 894-931. https://doi.org/10.1093/jeea/jvx028

Chivu, L. (2019). Local entrepreneurship and social services in Romania. Territorial analysis. European Research on Management and Business Economics, 25 (2), 79-86. https://10.1016/j. iedeen.2019.04.001

Crepon, B. \& van den Berg, G. J. (2016) Active Labor Market Policies. Annual Review of Economics, 8, 521546. https://doi.org/10.1146/annurev-economics-080614$\underline{115738}$ 
Gruznykh, S. (2015). New image of the employment service-improving the efficiency of labor market participants. Bulletin of Tomsk State University, 205208. https://doi.org/10.17223/15617793/400/33

Hadad, S. (2018). "The geographic distribution of Knowledge Economy (KE) within the European Union (EU)", Management \& Marketing. Challenges for the Knowledge Society, 13 (3), 1089-1107. https://doi.org/10.2478/mmcks-2018-0025.

Kluve, J. (2010). The Effectiveness of European Active Labor Market Policy. Labour Economics, 17, 904-918. https://doi.org/10.1016/j.labeco.2010.02.004

Martin, J. P. (2015). Activation and active labour market policies in OECD countries: stylised facts and evidence on their effectiveness. IZA Journal of labor policy, 4 (4), $1-29$. https://doi.org/10.1186/s40173-015-0032-y

Mušikić, S. R., Marčetić, M. N., \& Đurović, S. Đ. (2017). The role of the active policy of the labor market in the Republic of Serbia. Ekonomika, 63 (2), 79-86. https://doi.org/10.5937/ekonomika1702079M

\section{$\triangle$ Correspondence}

\section{Tatiana Stuken}

Dostoevsky Omsk State University Mira, 55-a, 644077, Omsk, Russia

E-mail: stuken@mail.ru
Law of the Russian Federation N 1032-1 (1991).

"Employment of the population in the Russian Federation". Retrieved May 30, 2020 from: http://www.consultant.ru/document/cons doc LAW 60/

Passport of the national project (program) "Productivity and employment support" (2018). Retrieved May 30, 2020 from:

http://static.government.ru/media/files/Ki3g5TzKdmVyX 2ogBvNTIxH3BQ6YFADA.pdf

Vooren, M., Haelermans, C., Maassen van den Brink, H. \& Groot, W. (2019). The Effectiveness of Active Labor Market Policies: A Meta-Analysis. Journal of Economic Surveys, 33 (1), 125-149.

https://doi.org/ 10.1111/joes.12269 